\title{
STRESS OF ANGLE SECTION SUBJECTED TO TRANSVERSAL LOADING ACTING OUT OF THE SHEAR CENTER
}

\author{
Filip Anić \\ Josip Juraj Strossmayer University of Osijek, Faculty of Civil Engineering Osijek, Student \\ Davorin Penava \\ Josip Juraj Strossmayer University of Osijek, Faculty of Civil Engineering Osijek, Assistant Professor \\ Corresponding author: dpenava@gfos.hr
}

\begin{abstract}
Angle or L-section bars are commonly used as non-structural elements in modern buildings, such as carriers of massive and expensive glass walls. While they are commonly loaded with shear forces, they can nonetheless be subjected to significant torsion, which occurs from loading outside the shear center, and can be omitted. This omission may result in lack of shear bearing capacity. Shear and additional normal stresses were investigated due to torsion and without one. Analytical calculations in the linear-elastic domain showed a significant increase in shear stresses due to torsion. In addition, we compared the results with numerical models to test the accuracy of the analytical calculations and the suitability of numerical models.
\end{abstract}

Keywords: Non-structural elements, angle bar, shear center, torsion, shear resistance

\section{NAPREZANJA KUTNOG PROFILA USLIJED DJELOVANJA POPREČNE SILE VAN CENTRA POSMIKA}

Sažetak: Kutne ili L profile primjenjujemo najčešće kao nekonstrukcijske elemente, naprimjer pri gradnji nosača teških i skupocjenih staklenih stijena. Pritom oni, iako izloženi isključivo poprečnom opterećenju, mogu biti pod značajnim utjecajem St. Venantovog uvijanja koje nastaje zbog djelovanja van centra posmika, a koje se može previdjeti. Posljedica toga može biti nedovoljna nosivost na posmik. Istražena su posmična te dodatno normalna naprezanja u slučaju s i bez uvijanja. Analitički proračuni u linearno-elastičnom području pokazali su značajan utjecaj uvijanja na razinu posmičnih naprezanja. Rezultati su dodatno uspoređeni s rezultatima numeričkih proračuna radi provjere točnosti i prikladnosti.

Ključne riječi: kutni profil, centar posmika, uvijanje, posmična naprezanja 


\section{INTRODUCTION}

In modern times, glass has become more and more popular among architects because of its aesthetic appeal and because of the trend toward energy-efficient buildings (Figure 1). This has led angle bars to become widespread non-structural elements (secondary elements), but which still must support heavy, expensive glass walls. However, because angle bars are secondary elements, engineers tend to overlook possible torsional effects.
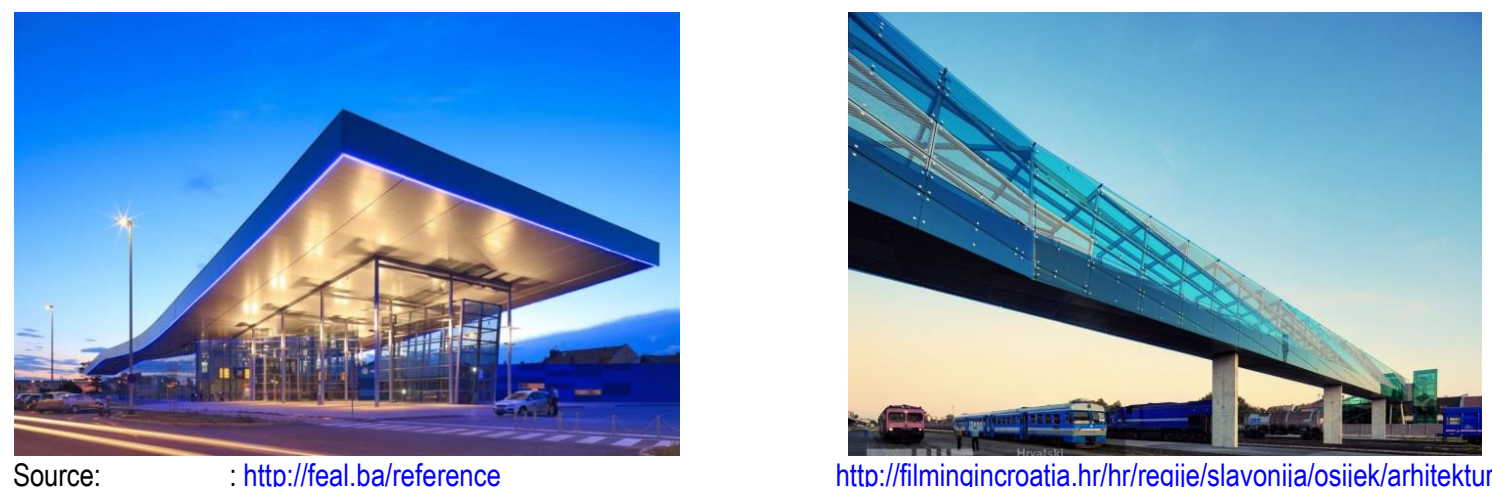

Figure 1 Steel and glass buildings in Osijek

For a given cross-section, there is a point where the resultant of transverse shear stresses passes. That point is called the shear center 0 . If a bar with an angled cross-section is loaded at the shear center, it will only bend (Figure 2a); however, if a transverse force is applied outside the shear center, the beam will bend and twist (Figure $2 b)$. In some cases, due to restrained torsion, the beam warps, additionally increasing the shear and normal stress [2] . Furthermore, because of their low torsional stiffness, thin-walled sections are extremely sensitive to transverse loading outside the shear center $[4,5]$. For the remainder of this paper, we refer to the force applied in the shear center as the "first problem" (Figure 3a) and the force applied outside the shear center as the "second problem" (Figure $3 b)$. We used $[6,7]$ to perform analytical calculations and [8] to produce graphics.

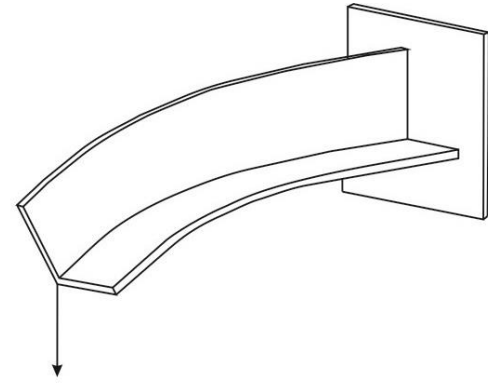

(a) Load applied in the shear center

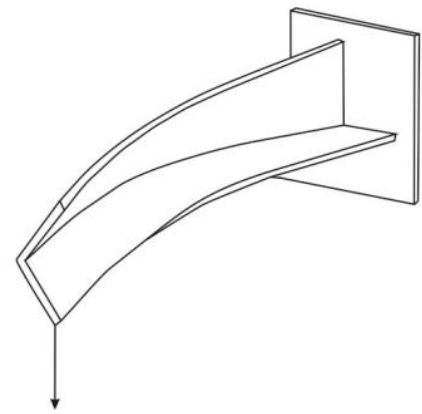

(b) Load applied outside the shear center

Figure 2 Beam subjected to transverse force

These two problems may have different normal stress, and certainly they will have different shear stress because of the torsional effect of the second problem. Shear stress is calculated using the shear flow method. The shear flow represents the change in the shear stress gradient, similar to the flow gradient in fluid mechanics 0 . On average, shear flow may seem difficult to calculate when dealing with asymmetric cross-sections and cross-sections that have principal axis not parallel to the local axis. Warping and the problems of restrained torsion shall be analyzed using Vlaslov's theory (1940). 


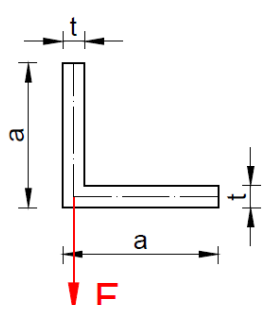

(a) First problem

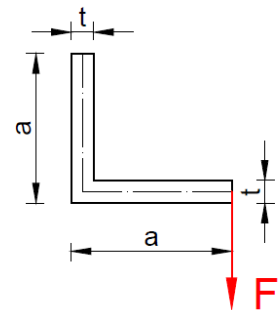

(b) Second problem

Figure 3 Position of loading, depending on the position of the shear center

\section{GEOMETRICAL CHARACTERISTICS}

The geometrical center of the angle section in Figure $4 \mathrm{a}$ is $y=\frac{a}{4}, z=\frac{a}{4}$. The force $F$ is at an arbitrary distance $e$ from the right end, and will cause a reaction $R_{y}$. The force equilibrium in the $y$ direction produces:

$$
\sum F_{y}=0 \Rightarrow-F+R_{y}=0 \Rightarrow F=R_{y}
$$

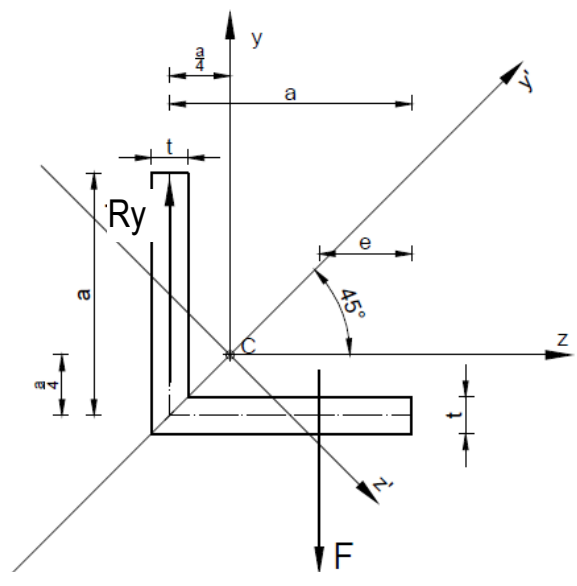

(a) Shear center

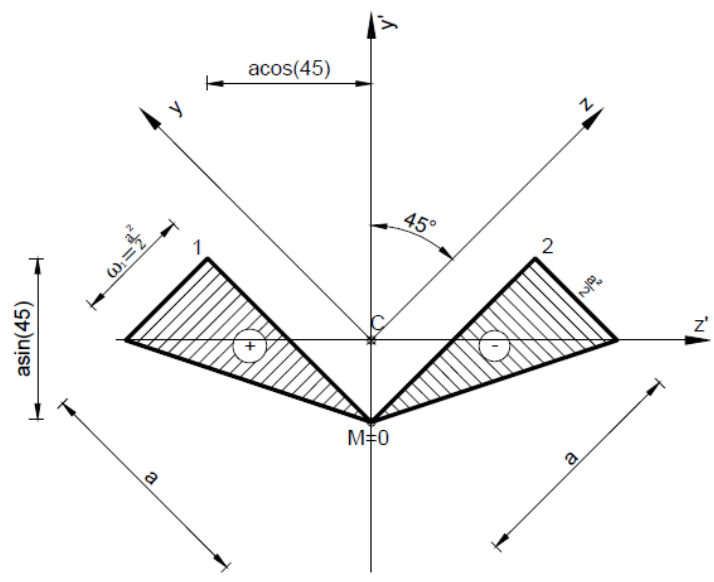

(b) Sectoral moments of inertia

\section{Figure 4 Illustrations of some geometrical characteristics}

Thus, in a torsional free section, the sum of the moments on the right end must be zero:

$$
\begin{aligned}
\sum M= & 0 \Rightarrow-R_{y} \cdot a+F \cdot e=0 \\
R_{y} a & =F e \Rightarrow F a=F e \\
e & =a
\end{aligned}
$$

Thus, the shear center is located at the intersection of the two flanges.

Note that transverse force is $V=F$. The principal axes $y^{\prime}$ and $z^{\prime}$ are located at $45^{\circ}$ from the local axis, so the moments of inertia about the principal axis are obtained as:

The torsional moment of inertia is:

$$
\begin{aligned}
& I_{y^{\prime}}=2\left[\frac{1}{3}\left(\frac{t}{\cos 45^{\circ}}\right)\left(a \cos 45^{\circ}\right)^{3}\right]=\frac{1}{3} t a^{3} \\
& I_{z^{\prime}}=2\left[\frac{1}{12}\left(\frac{t}{\cos 45^{\circ}}\right)\left(a \cos 45^{\circ}\right)^{3}\right]=\frac{1}{12} t a^{3}
\end{aligned}
$$

$$
I_{T}=\frac{1}{3} \sum h t^{3}=\frac{2}{3} a t^{3}
$$


The main sectorial coordinates are:

$$
\omega_{0}=0 ; \omega_{1}=-a \sin (45) \cdot a \cos (45)=-\frac{a^{2}}{2} ; \omega_{2}=a \sin (45) \cdot a \cos (45)=\frac{a^{2}}{2}
$$

Hence, the main sectorial moment of inertia (Figure 3b) are:

$$
I_{\omega}=\int_{A} \omega^{2} d A=t \cdot 2 \cdot\left(\frac{\frac{a^{2}}{2} \cdot a}{2} \cdot \frac{2}{3} \cdot \frac{a^{2}}{2}\right)=\frac{t a^{5}}{6}
$$

\section{FIRST PROBLEM}

\subsection{Shear stress}

Using superposition, the transverse force $\boldsymbol{V}$ can be divided onto the principal axes, producing $\boldsymbol{V}_{\boldsymbol{y}^{\prime}}$ and $\boldsymbol{V}_{\mathbf{z}^{\prime}}$. For $\boldsymbol{V}_{\boldsymbol{y}^{\prime}}$, rotate the section so that the $\boldsymbol{y}^{\prime}$ axis is the vertical axis, and imagine the cross-section as a pipe (hollow interior). Now, imagine pouring water into its ends. The flow of water represents the shear flow from $\boldsymbol{V}_{\boldsymbol{y}^{\prime}}$ (Figure 5a). Repeat this process for the $\mathbf{z}^{\prime}$ axis, obtaining the shear flow from $\boldsymbol{V}_{\mathbf{z}^{\prime}}$ (Figure $5 b$ ).

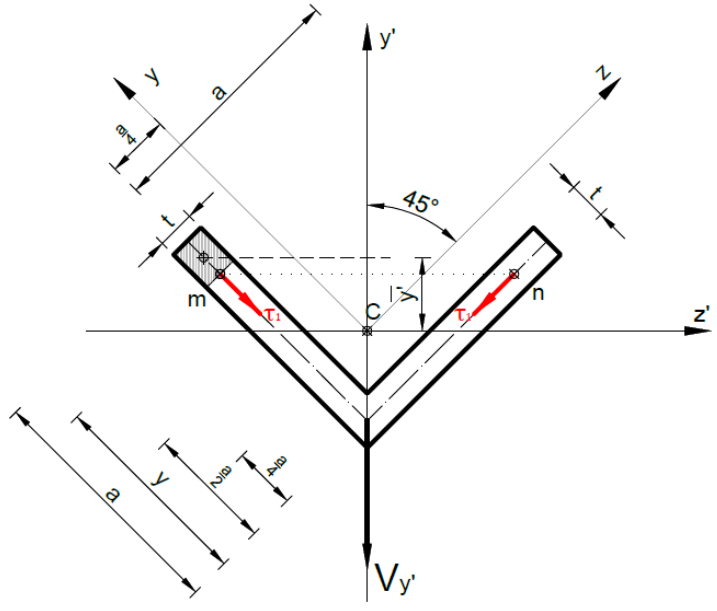

(a) Shear flow due to $V_{y^{\prime}}$

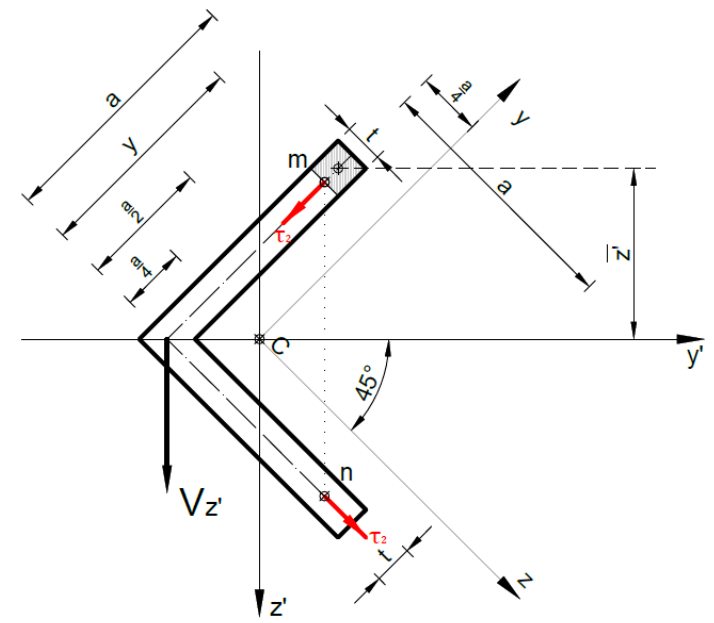

(b) Shear flow due to $V_{z^{\prime}}$

Figure 5 Shear flow due to $V$

The shear stress from $\boldsymbol{V}_{\boldsymbol{y}^{\prime}}$ is obtained by considering point $\boldsymbol{m}$ :

The first moment of area is:

$$
\overline{y^{\prime}}=\frac{a-y}{2} \cos 45^{\circ}+y \cos 45^{\circ}-\frac{a}{2} \cos 45^{\circ}=\frac{y}{2} \cos 45^{\circ}
$$

$$
S_{y^{\prime}}=t(a-y) \overline{y^{\prime}}=\frac{1}{2} t(a-y) y \cos 45^{\circ}
$$

Thus, the shear stress from $V_{y^{\prime}}$ is:

$$
\tau_{1}=\frac{V_{y^{\prime}} \cdot S_{y^{\prime}}}{I_{y^{\prime}} \cdot t}=\frac{3 V(a-y) y}{t a^{3}}
$$

Equivalently, point $\boldsymbol{n}$ will have the same function, which depends on $z: \tau_{1}=\frac{3 V(a-z) z}{t a^{3}}$

Similarly, to obtain the shear stress from $V_{z^{\prime}}$, consider point $\boldsymbol{m}$ :

$$
\overline{z^{\prime}}=\frac{a-y}{2} \cos 45^{\circ}+y \cos 45^{\circ}=\frac{y+a}{2} \cos 45^{\circ}
$$


The first moment of area is:

$$
S_{z^{\prime}}=t(a-y) \overline{z^{\prime}}=t(a-y) \frac{y+a}{2} \cos 45^{\circ}=\frac{t}{2}\left(a^{2}-y^{2}\right) \cos 45^{\circ}
$$

The shear stress is:

$$
\tau_{2}=\frac{V_{z}^{\prime} \cdot S_{z^{\prime}}}{I_{z^{\prime}} \cdot t}=\frac{3 V\left(a^{2}-y^{2}\right)}{4 t a^{3}}
$$

Similarly, point $\boldsymbol{n}$ will have the same function, which depends on $z: \tau_{2}=\frac{3 v\left(a^{2}-z^{2}\right)}{4 t a^{3}}$.

The total stress of the vertical flange is obtained by referring to the shear flow vectors $\tau_{\mathbf{1}}$ and $\tau_{\mathbf{2}}$ at a point $\boldsymbol{m}$ (Figure 6), where they have the same direction. Thus, it can be written as:

$$
\tau_{m}=\tau_{1}+\tau_{2}=\frac{3 V(a-y)(a+5 y)}{4 t a^{3}}, y \in[0, a]
$$

The total stress of the horizontal flange is obtained by referring to shear flow vectors $\tau_{\mathbf{1}}$ and $\boldsymbol{\tau}_{\mathbf{2}}$ at a point $\boldsymbol{n}$ (Figure 6), where they have opposite directions. Thus, it can be written as:

$$
\tau_{n}=\tau_{1}-\tau_{2}=\frac{3 V(a-z)(a-3 z)}{4 t a^{3}}, z \in[0, a]
$$

For the position of the maximum stress at the vertical flange, solving $\frac{d}{d y} \tau_{m}$ gives $y=\frac{2 a}{5}$; thus, the maximum stress is:

$$
\tau_{m, \max }=\frac{27 \mathrm{~V}}{20 a t}
$$

For the position of the maximum stress at the horizontal flange, solving $\frac{d}{d z} \tau_{n}$ gives $z=\frac{2 a}{3}$; thus, the maximum stress is:

$$
\tau_{n, \max }=-\frac{V}{4 a t}
$$

The horizontal flange has two opposite shear flows, and there is a point where they cancel. By solving $\boldsymbol{\tau}_{\boldsymbol{n}}=$ 0, this point is obtained as: $\mathbf{z}=\frac{\boldsymbol{a}}{3}$.

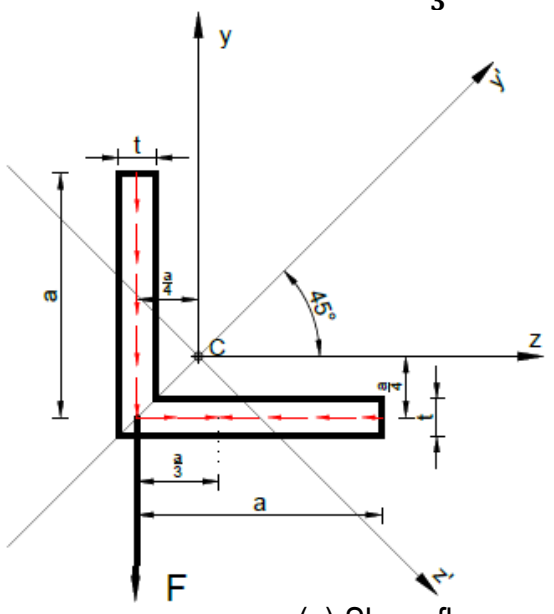

(a) Shear flow

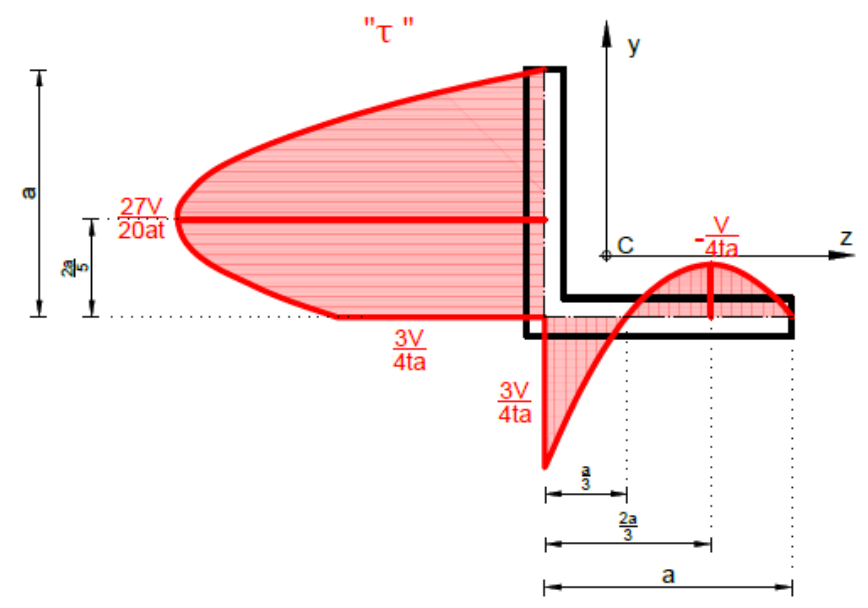

(b) Shear stress

\subsection{Normal stress}

Figure 6 Resulting shear flow and stress

Using superposition, $\boldsymbol{M}_{\boldsymbol{y}}$ is divided onto the principal axes, thus obtaining stress from $\boldsymbol{M}_{\boldsymbol{y}^{\prime}}$ and $\boldsymbol{M}_{\mathbf{z}^{\prime}}$ :

$$
\begin{gathered}
\sigma_{x}^{M_{y^{\prime}}}=\frac{M_{y^{\prime}}}{I_{y^{\prime}}} \cdot z^{\prime}=-\frac{F x \cos \left(45^{\circ}\right)}{I_{y^{\prime}}} \cdot z^{\prime}, z^{\prime} \in\left[-a \sin \left(45^{\circ}\right) ; a \cos \left(45^{\circ}\right)\right], x \in[0 ; L] \\
\sigma_{x}^{M_{z}^{\prime}}=\frac{M_{z^{\prime}}}{I_{z^{\prime}}} \cdot y^{\prime}=\frac{F x \sin \left(45^{\circ}\right)}{I_{z^{\prime}}} \cdot y^{\prime}, y^{\prime} \in\left[-\frac{a}{2} \sin \left(45^{\circ}\right) ; \frac{a}{2} \sin \left(45^{\circ}\right)\right], x \in[0 ; L]
\end{gathered}
$$

For the remainder of this paper, focus will be on the extreme values, i.e. $\boldsymbol{x}=\boldsymbol{L}$. 
The stress from $M_{z^{\prime}}$ at points 1 and 3 are $y^{\prime}=\frac{a}{2} \sin \left(45^{\circ}\right)$; note that $\sin \left(45^{\circ}\right)=\cos \left(45^{\circ}\right)$ :

$$
\sigma_{x, 1}^{M_{z^{\prime}}}=\sigma_{x, 3}^{M_{z^{\prime}}}=\frac{F \cdot L \cos \left(45^{\circ}\right)}{\frac{1}{12} t a^{3}} \cdot \frac{a}{2} \sin \left(45^{\circ}\right)=\frac{3 F L}{a^{2} t}
$$

Similarly, the stress at point 2 is $y^{\prime}=-\frac{a}{2} \sin \left(45^{\circ}\right) \Rightarrow \sigma_{x, 2}^{M_{z^{\prime}}}=-\frac{3 F L}{a^{2} t}$

The stress from $M_{y^{\prime}}$ at point 1 is $z=-a \sin \left(45^{\circ}\right)$

$$
\sigma_{x, 1}^{M_{y^{\prime}}}=-\frac{F \cdot L \sin \left(45^{\circ}\right)}{\frac{1}{3} t a^{3}} \cdot\left(-a \sin \left(45^{\circ}\right)\right)=\frac{3 F L}{2 a^{2} t}
$$

Similarly, the stress at point 3 is $z=a \sin \left(45^{\circ}\right) \Rightarrow \sigma_{x, 3}^{M y^{\prime}}=-\frac{3 F L}{2 a^{2} t}$

At point 2: $=\mathbf{0} \Rightarrow \boldsymbol{\sigma}_{\boldsymbol{x}, \mathbf{2}}^{\boldsymbol{M}_{\boldsymbol{y}^{\prime}}^{\prime}}=\mathbf{0}$.

The total normal stresses (Figure 7) at various points are:

- Point 1:

$$
\begin{gathered}
\sigma_{x, 1}=\sigma_{x, 1}^{M_{z}^{\prime}}+\sigma_{x, 1}^{M_{y^{\prime}}}=\frac{9 F L}{2 a^{2} t} \\
\sigma_{x, 2}=\sigma_{x, 2}^{M_{z}^{\prime}}+\sigma_{x, 2}^{M_{y^{\prime}}^{\prime}}=-\frac{3 F L}{a^{2} t} \\
\sigma_{x, 3}=\sigma_{x, 3}^{M_{z^{\prime}}}+\sigma_{x, 3}^{M_{y^{\prime}}}=\frac{3 F L}{2 a^{2} t}
\end{gathered}
$$

- Point 2:

The neutral axis is:

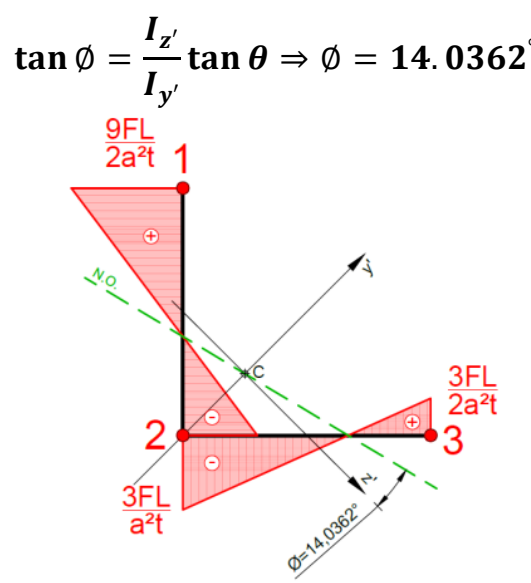

Figure 7 Schematic of the total normal stress

\section{SECOND PROBLEM}

\subsection{Shear stress}

In most types of open cross-sections under restrained torsion, the bars warp, increasing normal stress [2] However, the diagrams of sectorial moment of inertia are directly proportional to the distance from the point $\boldsymbol{M}$ (Figure $4 \mathrm{~b}$ ). This means there will be plane deformations but not longitudinal deformations. Therefore, $L$ sections do not warp, so the bimoment and moment of torsional warp are zero: $\boldsymbol{B}_{\boldsymbol{\omega}}=\boldsymbol{M}_{\boldsymbol{\omega}}=\mathbf{0}$. No warp connotation is typical for radial sections because the flanges or webs intersect at exactly one point [2]. Torsional moment can be divided onto pair of moment:

$$
T=M_{t}=M_{t s}+M_{\omega} \Rightarrow M_{x}=M_{t}=M_{t s}
$$

where $\boldsymbol{M}_{\boldsymbol{t}}$ is the pure torsional moment. Equation 26 shows that the torsional moment is the same as the pure torsional moment.

Due to the force eccentricity from the shear center, equivalent substitution of a force and moment is made (Figure 8). Hence, $\boldsymbol{T}=\boldsymbol{F} \cdot \boldsymbol{a}$, and $\boldsymbol{V}=\boldsymbol{F}$. 
The transverse force is placed at the shear center, producing the same stress as in the first problem (Sec. 3.1), plus additional stress due to torsion.

The maximum shear stress from torsion will occur on the section's borders:

$$
\tau_{\max }=\frac{T \cdot \rho}{I_{T}}=\frac{T \cdot t}{I_{T}}=\frac{3 F}{2 t^{2}}
$$

Where $\boldsymbol{\rho}$ is the distance measured from the centerline through the flange thickness. Note that the stress is the same for the horizontal and vertical flanges (Figure 9).

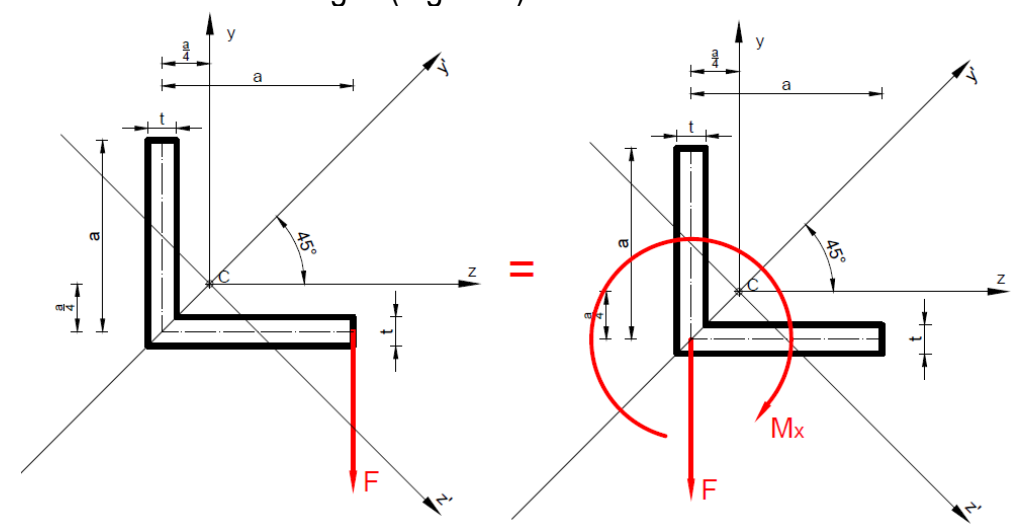

Figure 8 Force equivalent substitution

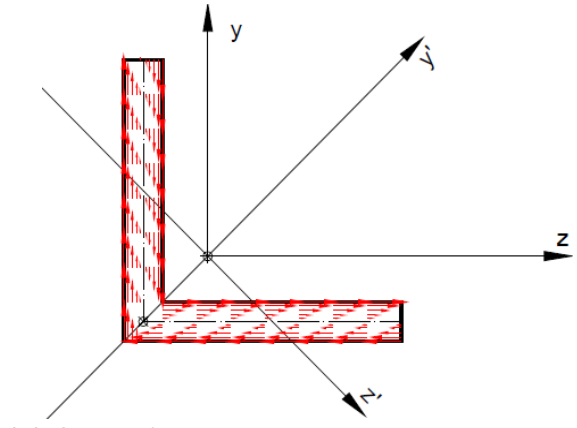

(a) Shear flow throughout thickness

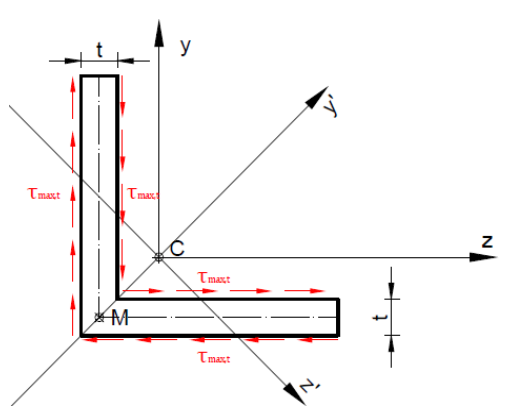

(b) Position of outer maximum shear stress

Figure 9 Shear flows caused by torsion

In theory of thin-walled structures, structure's thickness is much smaller than its other dimensions. Thus, the stress change through the thickness is negligible [2] . However, for torsion, the stress is clearly linearly changeable through the thickness due to $\boldsymbol{\rho}$ (Figure 9). When merging these two problems, it is reasonable to assume that the shear stress caused by the transverse force is constant through the thickness [3] .

Vertical flange, left corner Referring to the flow vectors $\boldsymbol{\tau}_{\mathbf{1}}, \boldsymbol{\tau}_{\mathbf{2}}$ (Figure 6 ), they clearly have the same direction. However, the flow vector $\boldsymbol{\tau}_{\boldsymbol{t}, \boldsymbol{m a x}}$ (Figure 9 ) has the opposite direction:

$$
\tau_{m, l}=\tau_{1}+\tau_{2}-\tau_{t, \text { max }}=\frac{3 V\left(-2 a^{3}+a^{2} t+4 a t y-5 t y^{2}\right)}{4 a^{3} t^{2}}, y \in[0, a]
$$

Vertical flange, right corner Referring to the flow vectors $\boldsymbol{\tau}_{1}, \boldsymbol{\tau}_{2}$, and $\boldsymbol{\tau}_{\boldsymbol{t}, \boldsymbol{m a x}}$ (Figures 6 and $9 \mathrm{~b}$ ), they all have the same direction:

$$
\tau_{m, d}=\tau_{1}+\tau_{2}+\tau_{t, \max }=\frac{3 V\left(2 a^{3}+a^{2} t+4 a t y-5 t y^{2}\right)}{4 a^{3} t^{2}}, y \in[0, a]
$$

Horizontal flange, upper corner Referring to the flow vectors $\tau_{2}, \tau_{t, m a x}$, they have the same direction. However, the flow vector $\boldsymbol{\tau}_{\mathbf{1}}$ has the opposite direction:

$$
\tau_{n, g}=\tau_{1}-\tau_{2}-\tau_{t, \text { max }}=\frac{3 V\left(\frac{t(a-3 z)(a-z)}{a^{3}}-2\right)}{4 t^{2}}, z \in[0, a]
$$

Horizontal flange, lower corner Referring to the flow vectors $\boldsymbol{\tau}_{\mathbf{1}}, \boldsymbol{\tau}_{\boldsymbol{t} \text {, max }}$ (Figures 6 and $9 \mathrm{~b}$ ), they have the same direction. However, the flow vector $\boldsymbol{\tau}_{\mathbf{2}}$ (Figure 6 ) has the opposite direction: 


$$
\tau_{n, i}=\tau_{1}-\tau_{2}+\tau_{t, \max }=\frac{3 V\left(\frac{t(a-z)(a-3 z)}{a^{3}}+2\right)}{4 t^{2}}, z \in[0, a]
$$

The stress at $\boldsymbol{y}=\mathbf{0}$, right corner, vertical flange is:

$$
\tau_{d, y=0}=\frac{3 V(2 a+t)}{4 a t^{2}}
$$

The stress at $\boldsymbol{y}=\mathbf{0}$, left corner, vertical flange is:

$$
\tau_{l, y=0}=\frac{3 V(t-2 a)}{4 a t^{2}}
$$

The stress at $\mathbf{z}=\mathbf{0}$, lower corner, horizontal flange is:

$$
\tau_{g, z=0}=\frac{3 V\left(\frac{t}{a}+2\right)}{4 t^{2}}
$$

The stress at $\mathbf{z}=\mathbf{0}$, upper corner, horizontal flange is:

$$
\tau_{i, z=0}=\frac{3 V\left(\frac{t}{a}-2\right)}{4 t^{2}}
$$

The stress given by Eq. 34 is also the maximum stress at the lower corner of the horizontal flange (see Figure 10). The position of the maximum stress of the vertical flange, right corner is found by solving $\frac{d}{d y} \tau_{m, d} \Rightarrow y=\frac{2 a}{5}$. Thus, the stress is:

$$
\tau_{m, \max , d}=\frac{3 V(10 a+9 t)}{20 a t^{2}}
$$

The position of minimum stress on the vertical flange, left corner is $\frac{d}{d y} \tau_{m, l} \Rightarrow y=\frac{2 a}{5}$. Thus, the stress is:

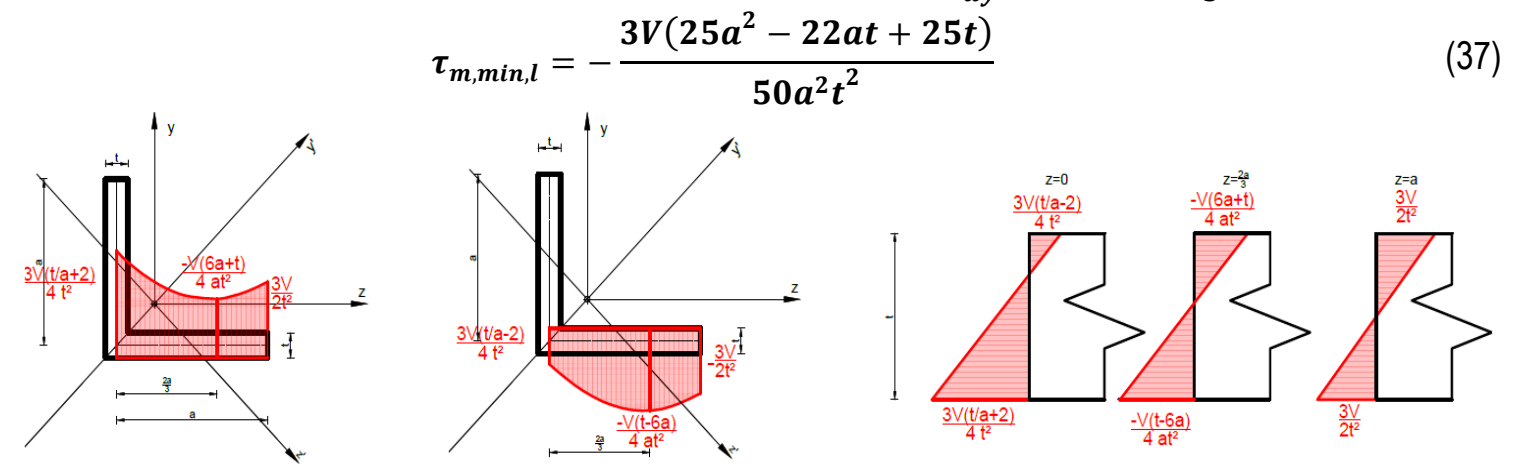

(a) Maximum shear stress of the horizontal flange
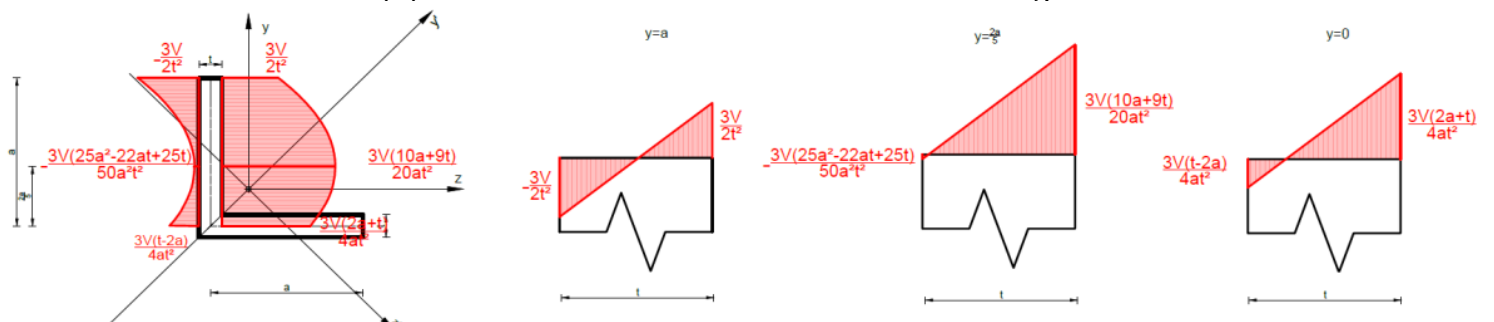

(b) Maximum shear stress of the vertical flange

Figure 10 Total shear stress

The position of maximum stress on the horizontal flange, upper corner is $\frac{d}{d z} \tau_{n, g} \Rightarrow z=\frac{2 a}{3}$. Thus, the stress is:

$$
\tau_{n, \text { max }, g}=-\frac{v(6 a+t)}{4 a t^{2}}
$$

The position of minimum stress on the horizontal flange, lower corner is $\frac{d}{d z} \tau_{n, i} \Rightarrow z=\frac{2 a}{3}$. Thus, the stress is:

$$
\tau_{n, \min , i}=-\frac{V(t-6 a)}{4 a t^{2}}
$$




\subsection{Normal stress}

As explained in Sec 4.1, there is no additional normal stress, so the equations of restrained torsion become:

$$
\sigma_{x}=\frac{M_{z^{\prime}}}{I_{z^{\prime}}} y^{\prime}+\frac{M_{y^{\prime}}}{I_{y^{\prime}}} z^{\prime}+\frac{B_{\omega}}{I_{\omega}} \omega \Rightarrow \sigma_{x}=\frac{M_{z^{\prime}}}{I_{z^{\prime}}} y^{\prime}+\frac{M_{y^{\prime}}}{I_{y^{\prime}}} z^{\prime}
$$

This stress is the same as that in problem one, described in Sec. 3.2.

\section{NUMERICAL SIMULATIONS}

To test the analytical calculations calculated using [6] with no warping connotation, we performed six numerical simulations in AutoDesk: Robot Structural Analysis Professional 2014 [9] . The initial parameters given were: $\boldsymbol{L}=$ $3000 \mathrm{~mm}, \quad \boldsymbol{a}=\mathbf{2 0 0} \mathrm{mm}, \boldsymbol{t}=\mathbf{1 0} \mathrm{mm}, \boldsymbol{F}=1000 \mathrm{~N}$, structural steel $S 275$. The main model characteristics are as follows.

Model 1: Composed of two thin plates, shear force applied in shear center, computed by membrane theory

Model 2: Modeled in thin-walled section designer, shear force applied in shear center

Model 3: Modeled in solid section designer, applied shear force

Model 4: Modeled in solid section designer, applied torsion

Model 5: A volumetric model, loaded by shear force in the shear center

Model 6: A volumetric model, loaded by shear force outside the shear center

Note that all models were analyzed for normal stress, observed at each section's midline. The stress was read at the following positions (Figure 11Figure 1) $(\mathbf{z} ; \boldsymbol{y})$ : $1(0 ; 200), 2(0 ; 80), 3(0 ; 0), 4(133.33 ; 0), 5(200 ; 0)$. In addition, the 3D models were read for shear stress at the midpoint of their span, and read for normal stress at the end of their span. Stress was read in the solid sections at their midline.

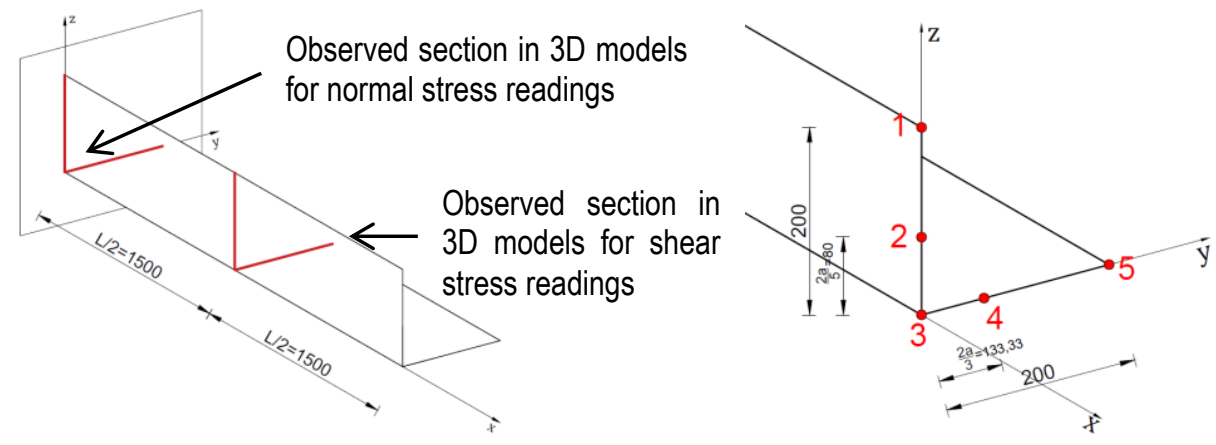

Figure 11 Positions of stress readings in numerical models

Tables 1, 2 and 3 compare the analytical and numerical models in the points specified above, with their average difference as a percentage. Table 1 (and Figure 12) compares the shear stresses of the first problem.

Table 2 (and Figure 13) compares the stresses of the second problem; note that this table is split in two, comparing model 6 (the volumetric model) and model 4 (a solid section model loaded only with torsion) with equivalent analytical stress. Table 3 (and Figure 14), however, compares models normal stresses, considering only the 1st, 3rd and 5th points (Figure 11).

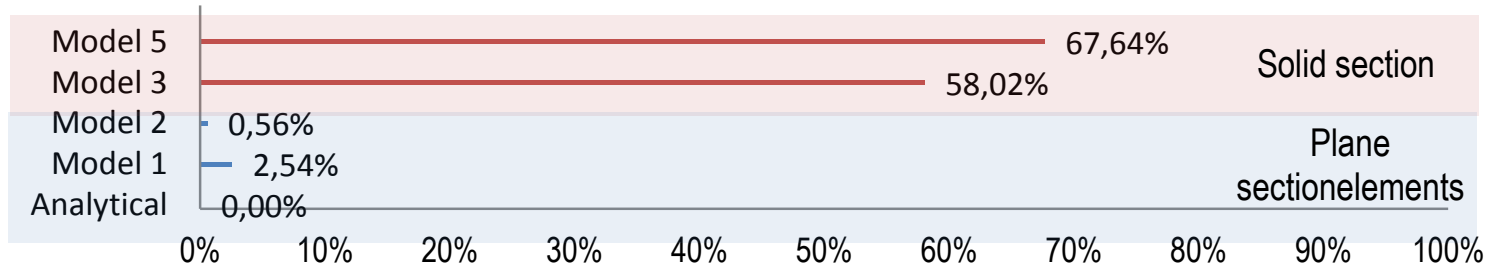

Figure 12 Average difference of the first problem between analytical and numerical models 


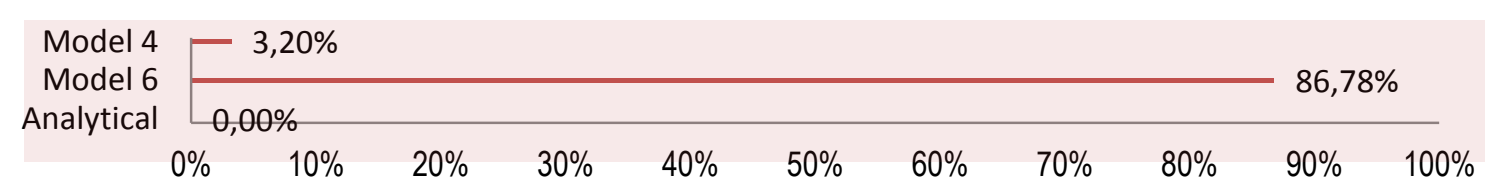

Figure 13 Average difference of the second problem between analytical and numerical models

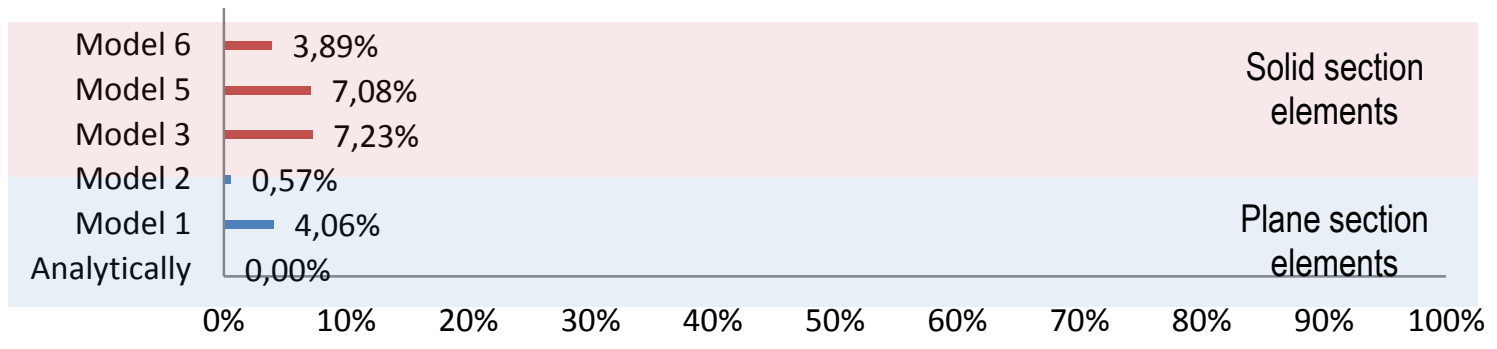

Figure 14 Average difference between the normal stresses of the analytical and numerical models

Table 1 Difference between shear stresses of the first problem for $F=1000.00 \mathrm{~N}$

\begin{tabular}{|c|c|c|c|c|}
\hline Simulation & Position & Stress value $\mathrm{N} / \mathrm{mm}^{2}$ & Difference & Average difference \\
\hline \multirow{5}{*}{ 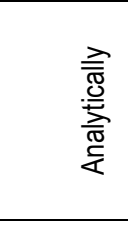 } & 1 & 0.00 & $0.00 \%$ & \multirow{5}{*}{$0.00 \%$} \\
\hline & 2 & 0.34 & $0.00 \%$ & \\
\hline & 3 & 0.19 & $0.00 \%$ & \\
\hline & 4 & 0.06 & $0.00 \%$ & \\
\hline & 5 & (200 & $000 \%$ & \\
\hline \multirow{5}{*}{$\begin{array}{l}\bar{\Phi} \\
\frac{0}{D} \\
\dot{\nu}\end{array}$} & 1 & 0.00 & $0.00 \%$ & \multirow{5}{*}{$2.54 \%$} \\
\hline & 2 & 0.34 & $1.70 \%$ & \\
\hline & 3 & 0.17 & $7.34 \%$ & \\
\hline & 4 & 0.06 & $3.68 \%$ & \\
\hline & 5 & 0.00 & $0.00 \%$ & \\
\hline \multirow{5}{*}{$\begin{array}{l}\bar{\Phi} \\
\frac{0}{0} \\
\text { N }\end{array}$} & 1 & 0.00 & $0.00 \%$ & \multirow{5}{*}{$0.56 \%$} \\
\hline & 2 & 0.34 & $0.15 \%$ & \\
\hline & 3 & 0.19 & $0.27 \%$ & \\
\hline & 4 & 0.06 & $2.40 \%$ & \\
\hline & 5 & 0.00 & $0.00 \%$ & \\
\hline \multirow{5}{*}{$\begin{array}{l}\bar{\Phi} \\
\frac{\bar{\phi}}{0} \\
\sum_{j}\end{array}$} & 1 & 0.14 & $100.00 \%$ & \multirow{5}{*}{$58.02 \%$} \\
\hline & 2 & 0.16 & $51.70 \%$ & \\
\hline & 3 & 0.14 & $24.80 \%$ & \\
\hline & 4 & 0.07 & $13.60 \%$ & \\
\hline & 5 & 0.16 & $100.00 \%$ & \\
\hline \multirow{5}{*}{$\begin{array}{l}\bar{\Phi} \\
\sum_{i}^{\circ}\end{array}$} & 1 & 0.16 & $100.00 \%$ & \multirow{5}{*}{$67.64 \%$} \\
\hline & 2 & 0.33 & $2.22 \%$ & \\
\hline & 3 & 0.09 & $52.00 \%$ & \\
\hline & 4 & 0.01 & $84.00 \%$ & \\
\hline & 5 & 0.05 & $100.00 \%$ & \\
\hline
\end{tabular}


Stress of angle section subjected to transversal loading acing out of the shear center

Table 2 Difference between shear stress of the second problem $F=1000.00 \mathrm{~N}$

\begin{tabular}{|c|c|c|c|c|c|}
\hline Simulation & Position & $\begin{array}{c}\text { Stress value inner } \\
\text { side } \mathrm{N} / \mathrm{mm}^{2}\end{array}$ & $\begin{array}{c}\text { Stress value outer } \\
\text { side } \mathrm{N} / \mathrm{mm}^{2}\end{array}$ & Difference & $\begin{array}{l}\text { Average } \\
\text { difference }\end{array}$ \\
\hline \multirow{5}{*}{ 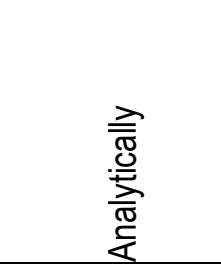 } & 1 & 3.75 & 3.75 & $0.00 \%$ & \multirow{5}{*}{$0.00 \%$} \\
\hline & 2 & 3.42 & 4.09 & $0.00 \%$ & \\
\hline & 3 & 3.56 & 3.56 & $0.00 \%$ & \\
\hline & 4 & 3.56 & 3.69 & $0.00 \%$ & \\
\hline & 5 & 3.75 & 3.75 & $0.00 \%$ & \\
\hline \multirow{5}{*}{$\begin{array}{l}\overline{0} \\
\overline{0} \\
\sum_{0}^{0}\end{array}$} & 1 & 0.27 & 0.27 & $92.80 \%$ & \multirow{5}{*}{$86.78 \%$} \\
\hline & 2 & 0.32 & 0.95 & $90.64 \%$ & \\
\hline & 3 & 0.44 & 0.76 & $87.64 \%$ & \\
\hline & 4 & 0.47 & 0.67 & $86.81 \%$ & \\
\hline & 5 & 0.90 & 0.90 & $76.00 \%$ & \\
\hline \multicolumn{6}{|l|}{ Pure torsion } \\
\hline \multicolumn{2}{|c|}{ Analytical maximum stress } & 3.75 & 3.75 & & $0.00 \%$ \\
\hline \multicolumn{2}{|l|}{ 4. Model } & 3.63 & 3.63 & & $3.20 \%$ \\
\hline
\end{tabular}

Table 3 Difference between normal stresses of the first and second problem $F=1000.00 \mathrm{~N}$

\begin{tabular}{|c|c|c|c|c|}
\hline Model & Position & Stress value $\mathrm{N} / \mathrm{mm}^{2}$ & Difference & Average difference \\
\hline \multirow{3}{*}{ 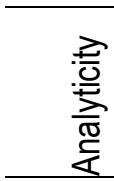 } & 1 & 16.89 & $0.00 \%$ & \multirow{3}{*}{$0.00 \%$} \\
\hline & 3 & 11.25 & $0.00 \%$ & \\
\hline & 5 & 5.63 & $0.00 \%$ & \\
\hline \multirow{3}{*}{$\leftarrow$} & 1 & 18.51 & $9.70 \%$ & \multirow{3}{*}{$4.06 \%$} \\
\hline & 3 & 12.01 & $6.79 \%$ & \\
\hline & 5 & 5.84 & $3.81 \%$ & \\
\hline \multirow{3}{*}{ i } & 1 & 16.74 & $0.00 \%$ & \multirow{3}{*}{$0.57 \%$} \\
\hline & 3 & 11.13 & $1.05 \%$ & \\
\hline & 5 & 5.52 & $1.80 \%$ & \\
\hline \multirow{3}{*}{$\dot{m}$} & 1 & 18.37 & $8.86 \%$ & \multirow{3}{*}{$7.23 \%$} \\
\hline & 3 & 13.69 & $21.69 \%$ & \\
\hline & 5 & 5.94 & $5.60 \%$ & \\
\hline \multirow{3}{*}{ is } & 1 & 17.83 & $2.94 \%$ & \multirow{3}{*}{$7.08 \%$} \\
\hline & 3 & 11.07 & $19.17 \%$ & \\
\hline & 5 & 5.15 & $13.30 \%$ & \\
\hline \multirow{3}{*}{$0^{\circ}$} & 1 & 15.99 & $5.24 \%$ & \multirow{3}{*}{$3.89 \%$} \\
\hline & 3 & 11.10 & $1.33 \%$ & \\
\hline & 5 & 6.35 & $12.89 \%$ & \\
\hline
\end{tabular}




\section{DISSCUSION AND CONCLUSION}

We expected that the shear stress given by the numerical simulations would strongly differ due to shear flow. However, Tables 1 and 2 show that three numerical simulations (1st, 2nd, and 4th) match well with the analytical calculation, confirming that the analytical calculation is accurate. Mismatches were found in the solid (volumetric) models, except for pure torsion in model 4 (see Table 2). We believe the solid-volumetric models yielded inaccurate data because it must account for thickness, while the thin-walled calculations do not. Nonetheless, accounting for thickness is essential for determining stress caused by torsion; therefore, model 4 yielded values equivalent to the analytical model. However, regardless of the model type, the normal stress matched excellently. This result confirms that the solid models were modeled correctly. Note that, in the models of the second problem, introducing restrained torsion did not significantly increase the normal stress; at some points, it even decreased. This result confirms the belief that no warping occurs in this case.

Comparing first and second problem clearly very different values of shear stress. The difference between the maximum stresses on the horizontal flange is as follows:

Expressed by the ratio:

$$
\Delta \tau_{H}=\tau_{n, \max , g}-\tau_{n, \max }=3.73-0.0625=3.67 \mathrm{~N} / \mathrm{mm}^{2}
$$

$$
\begin{aligned}
\tau_{n, \max , g}: \tau_{n, \max } \\
3.73: 0,0625 \\
59.68: 1
\end{aligned}
$$

The difference between maximum shear stresses on the vertical flange is:

Expressed by the ratio:

$$
\Delta \tau_{V}=\tau_{m, \max , d}-\tau_{m, \max }=4.09-0.3375=3.7525 \mathrm{~N} / \mathrm{mm}^{2}
$$

$$
\begin{aligned}
\tau_{m, \max , d}: \tau_{m, \max } \\
4.09: 0.3375 \\
12.11: 1
\end{aligned}
$$

It is clear that a force outside the shear center increases the shear stress by up to 60 times on the horizontal flange, and up to 12 times on the vertical flange. We conclude that the eccentricity from the shear center cannot be ignored. However, for restrained torsion, the $L$ section does not warp, producing no additional normal stress. In accordance with stated, shifting the transversal load from the shear center along the transversal axis will not increase the normal stresses. Considering the numerical models, we found that the plane models are superior for thin-walled analysis. Unfortunately, they could not be subjected to torsion (particular software [9] ). However, solid models subjected to pure torsion gave accurate results (Table 2). Thus, for loading outside shear center, one must combine a plane models (for stress from shear force) and solid models (for stress from torsion). In addition, both plane and solid models are suitable for normal stress analysis (Table 3).

\section{References}

[1] Urugal, A. C.; Fenster S. K., 2003: Advanced Strength and Applied Elasticity. 4th edition, Pearson Education, New Jersey

[2] Šimić, D., 2007: Teorija tankostijenih nosača otvorenog poprečnog presjeka. 1st edition, Filedata d.o.o., Zagreb

[3] Šimić, V. 1995: Otpornost materijala 2. 1st edition, Školska knjiga, Zagreb

[4] Pavazza, R., 2007: Uvod u analizu tankostijenih štapova. GIPA d.o.o., Zagreb

[5] Instiute for Steel Development \& Growth, Beams subjected to torsion and bending -I [Online]. Available from: http://www.steel-insdag.org/TeachingMaterial/Chapter17.pdf.

[6] Wolfram Research, Inc., 2012: Mathematica, Version 9.0.0.0, Champaign, IL (2012).

[7] Microsoft corp., Microsoft Mathematics, Version 4.0., Microsoft Redmond Campus, Redmond, Washington, U.S.

[8] Autodesk, Inc., AutoCAD, Version 2014, 111 Mclnnis Parkway, San Rafael, CA 94903, USA.

[9] Autodesk, Inc., 2014: Robot Structural Analysis Professional, Version 2014, 111 Mclnnis Parkway, San Rafael, CA 94903, USA. 